\title{
Multidimension Limits and Resolution Strategies for Tourism Targeted Poverty Alleviation in Deep Poverty Areas-Taking Sichuan Tibetan as an Example
}

\author{
Zhibing Li ${ }^{1,2}$, Yiran Xiao ${ }^{1,4}$, Sineng $\mathrm{Bi}^{3}$, Jianguo $\mathrm{Wu}^{1}$ \\ ${ }^{1}$ Southwest Minzu University, Chengdu, 610041, China \\ ${ }^{2}$ Aba Teacher's University, Aba, 623002, China \\ ${ }^{3}$ Qujing Public Security Bureau, Qujing, 655000, China \\ ${ }^{4}$ Southwest Petroleum University, Chengdu, 610500, China
}

Keywords: Deep poverty, Sichuan Tibetan area, Tourism targeted poverty alleviation, multidimension limits.

\begin{abstract}
Deep poverty in Sichuan Tibetan area is mainly manifested as low regional development level, complex poverty status and weak endogenous development capacity. Tourism-targeted poverty alleviation as an effective way to reduce poverty in Sichuan Tibetan area is also in face of constraints in infrastructure, human capital, fund, market, policy system and identification mechanism. Thus, this paper proposes five resolution strategies: accelerating tourism infrastructure construction, improving the endogenous development capacity of poverty population, expanding financing channels, optimizing market environment and deepening institutional reform so as to alleviate deep poverty in Sichuan Tibetan areas.
\end{abstract}

\section{Multidimension limits of tourism targeted poverty alleviation in Sichuan Tibetan areas}

Since from China's Western Development, especially with the launch of "targeted poverty alleviation program" as the overall keynote in recent years, Sichuan Tibetan area has made full use of abundant tourism resources to vigorously carry out tourism targeted poverty alleviation work. In 2015, Sichuan Tibetan tourism was included in provincial tourism poverty alleviation system. 32 impoverished counties and 243 poverty-stricken villages were included in the "Sichuan Rural Tourism Wealth Project Implementation Plan" and the "Sichuan Tourism Poverty Alleviation Five-Year Action Plan". There are more than 4,000 Tibetan farmhouses and more than 4000 pasture houses in Sichuan Tibetan area until 2016, which promoted employment for more than 100,000 farmers and herdsmen, received 51.293 million tourists, and achieved a total tourism income of RMB 45.077 billion. However, because of the complex poverty status, tourism targeted poverty alleviation in Sichuan Tibetan area is still facing multi-dimension limits while taking certain effects.

\subsection{Limits in infrastructure dimension}

The backwardness of infrastructure and related supporting service is a major weakness of tourism targeted poverty alleviation in poverty-stricken areas. At present, Sichuan Tibetan area is facing the problem that existing facilities cannot satisfy the tourism development demands and the double predicament of great difficulties in building new infrastructure, high cost and maintenance difficulties. Sichuan Tibetan area is located in the vital part of the Hengduan Mountain with the most complex natural environment under the influence of altitude, topography, geology, climate and other factors. It is hard to conduct infrastructure construction with higher capital investment than the general areas. Infrastructures seriously damaged by frequent earthquakes, mudslides, mountain collapses and other natural disasters are difficult for maintenance, which brings great impact on distribution of tourists and the transportation of native products. By the end of 2014, the population density in Sichuan Tibetan area was only 8.49 people per square kilometer, much lower than the total provincial average level of 167.49 people per square kilometer. The special population distribution 
form has brought huge challenges to infrastructure and public services. Insufficient radiation area of transportation, medical care, sanitation and other infrastructure, limited service ability make it very inconvenient for tourists' travelling and sightseeing.

\subsection{Limits in human capital dimension}

The quantity and quality of labor are two key factors influencing tourism practitioners to play a role in tourism production activities. The human resources in tourism development of Sichuan Tibetan area are in face of limits in two dimensions: insufficient number of employees, scarce capacity and low labor quality of employees. Under the influence of geographical environment, blood relationship, religion and other factors, the social structure in Sichuan Tibetan area shows a "block-style" feature. It is difficult to establish "weak" connection between "blocks", which may make poverty population reject heterogeneous resources and concepts. With closed concept and awareness, some poverty population get used to depending on traditional production mode for survival without strong intention to participate in tourism, and a limited number of people obtain employment in tourism industry. At a low level of population cultural quality and scientific literacy in Sichuan Tibetan area, the average educational period is only 6.4 years. Data of the sixth national census show that the illiteracy proportions of Aba and Ganzi reach up to $12.39 \%$ and $30.17 \%$. The illiteracy and semiliterate rate is particularly high among middle-aged and elderly people who have poor ability to accept scientific knowledge. With the development of the local tourism industry, the poverty population may also face challenges of decreased farmland and pasture, rising price, competition for employment opportunities with migrant labors, and social structure change. Once had to grasp development opportunities, they will be trapped in poorer situation.

\subsection{Limits in fund dimension}

Tourism as a typical capital-intensive industry demands abundant capital investment. Due to low economic development level in Sichuan Tibetan area, the launch of tourism targeted poverty alleviation work is limited. From the perspective of county-level fiscal revenue, the fiscal revenues increment at the corresponding county-level in Sichuan Tibetan area are mainly from the secondary and tertiary industries and the mineral resources tax. However, Sichuan Tibetan area with unreasonable thrice industrial structure, i.e. a relatively higher proportioned primary industry and lower proportioned secondary industry, lack large-scale industrial bases and leading enterprises. Industrial development makes extremely limited contribution to county-level finance. From the perspective of fund-raising mechanism, poverty alleviation program directly undertaken and promoted by government seldom keeps up with market. Due to certain conflicts between social financial institutions' market-oriented operation requirements for funds and the governmental policy arrangements for poverty alleviation, it is difficult to establish an effective integrative development mechanism between both, causing difficulties in financing and making people hard to obtain loans and financial services needed for development. From the perspective of urban development level, there exist huge differences of economic development levels in counties and towns of Sichuan Tibetan area characterized with obvious duality in regional, urban and rural development. Urban economic development cannot provide sufficient support for rural tourism resource development. From the perspective of the income of poverty population, they can only maintain food and clothing by their income without enough self-accumulation and savings. They lack material and financial capital for tourism operations. Due to the limit of fund shortage, poverty population are easily excluded from tourism industry development. Most positive effects of the tourism economy are enjoyed by people with certain material basis and social capital in the community. Thus, it is still veery hard for poor villagers to benefit from tourism development.

\subsection{Limits in market dimension}

Tourism targeted poverty alleviation as one of paths for poverty alleviation in the industry can mainly provide a platform for poverty villagers and households to develop tourism, provide opportunities to participate in tourism. Compared with general poverty alleviation, tourism targeted 
poverty alleviation emphasizes the role of market. Whether tourism is a successful tool for poverty alleviation relies not only on the subjective efforts of the government and local people, but also on tourists' cooperation. Tourists' buying tourism products is an economic behavior, the economic "rationality" of which is manifested in pursuing the maximum product utility. Therefore, not with "poverty alleviation" as the primary purpose of tourism consumption, they focus on whether the product quality can satisfy their tourism demands when choosing choose tourism products. The world economic development tendency, monetary policy, the new situation of national economic development, and the development status of surrounding tourist destinations will also have impact on the tourism development of Sichuan Tibetan area.

\subsection{Limits in policy and system dimension}

Policy and system as the main driving forces to solve poverty problem will sometimes cause decrease in development opportunities, thus leading to policy or institutional poverty. The special ecological location of Sichuan Tibetan area determines to give priority to ecological protection, and sets high "ecological threshold" for industrial development at the same time, which has objectively limited certain benefit-growth economic activities. Poverty population under the limitation of their own development capacity mainly adopts extensive resource utilization as a main way for survival. Under the main functional area positioning and ecological environment shield construction, the relations between ecological resources of Sichuan Tibetan area and the ecological economic activities of farmers and herdsmen keeps weakening or even breaking. Farmers and herdsmen become poor due to rich concentration of ecological resources. Fiscal transfer payment is the main form to carry out eco-compensation in Sichuan Tibetan area. But there still exist certain gap between the compensation standard and residents' income from traditional production and operation. So, this will have certain influence on poverty population's initiative to participate in tourism and ecological agriculture (pasture). Meanwhile, whether policy and system are sound enough is also influencing the effectiveness of tourism targeted poverty alleviation.

\subsection{Limits in identification mechanism dimension}

Tourism targeted poverty alleviation as a development-oriented and open-type way which requires to satisfy meet certain conditions for its implementation. This poverty alleviation method is not always suitable anywhere, nor suitable for anyone to participate. Therefore, it requires for precision identification of target areas and target groups including development condition identification, project identification and target population identification. Regarding development conditions, it requires for precision identification of the market conditions such as tourism, manpower, social resources and infrastructure, industrial infrastructure, policy system and other supporting conditions, source market capacity, and other market conditions. In terms of project, it requires for precision identification of project sustainability, economic effectiveness, social effectiveness, ecological benefits, and economic benefits and non-economic benefits. For target population, their intention and the ability to participate of the poverty population must be identified.

\section{Strategies for tourism targeted poverty alleviation in Sichuan Tibetan areas}

\subsection{Accelerate tourism infrastructure construction}

Transportation, electricity power, communications, water conservancy, other infrastructure and related supporting service are basic requirements to improve tourism service quality and bearing capacity. Tourism targeted poverty alleviation infrastructure construction in Sichuan Tibetan area should focus on following aspects: strengthen the construction, upgrading and reconstruction of electricity power, communication and drinking water, make efforts to solve "end project" problems in poverty-stricken areas, and improve the basic living conditions of the poverty population; carry out unified planning and construction of signs, marks, tourist service centers and landscape platforms along the tourism expressways; accelerate the construction of tourism parking lots, tourist service 
centers, sanitary toilets, medical rescue, security protection, and public service system, enhance tourism carrying and reception capacity.

\subsection{Improve the endogenous development capacity of poverty population}

Tourism targeted poverty alleviation is a typical "hematopoietic-type" poverty alleviation and the endogenous development capacity of poverty population is the key to its "continuous hematopoiesis". Lack of tourism occupational skill is an important factor limiting the poverty population to participate in tourism development. Skill training for needed people in Sichuan Tibetan area to participate in tourism development should be provided with targeted training contents based on the precondition of their own actual situation. People difficult to directly participate in tourism development can be trained to strengthen their ecological agricultural and husbandry skills, and provide ecological agriculture and ecological animal husbandry products for tourism development, expand their channels to indirectly participate in tourism development without changing the way of making a living.

\subsection{Expand financing channels}

Capital injection is a key factor to smoothly carry out tourism targeted poverty alleviation work. Sichuan Tibetan area can expand financing channels from following aspects when promoting tourism targeted poverty alleviation, take tourism as a leading industry for poverty alleviation, accelerate to build a national tourism poverty alleviation pilot zone, vigorously carry out the rural tourism wealth projects, conduct pilot projects for poverty alleviation in poverty villages, try to obtain special funds from the central government, provincial-level supporting funds, and enhance fiscal transfer payment strength, establish a financing platform and adopt multiple capital operation modes, such as TOT model(Transfer-Operate-Transfer-operate-transfer), PPP mode (Public-Private-Partnerships public-private partnership), BT model (Build Transfer-transfer), and lead social capital to enter tourism poverty alleviation and development field, set up tourism poverty alleviation investment development fund to support famers' small-amount financing by pledging agricultural land use rights, provide low-interest or interest-free loans, and provide industrial development capital support for the needy people.

\subsection{Optimize market environment}

Good market environment is not only the important condition for the stable tourism industry development in Sichuan Tibetan area, but also the important guarantee to improve the effectiveness of tourism targeted poverty alleviation. Sichuan Tibetan area should gradually adjust the product structure according to market demand and actual resource situation, create a "original ecology and original life" tourism product system, and call for "low-carbon, low-disturbance, low-intensity" tourism mode, and takes quality and efficiency type tourism development road of "maximum benefit and minimum destruction", guide the poverty population to provide peripheral products for self-driving tour, independent travel, "backpackers" and other travelling forms, establish the overall marketing concept, highlight the theme of "China's most beautiful Tibetan area", integrate advantageous natural and cultural resources of "two prefectures and one county" in a unified brand and image, and mobilize the development of related industries such as catering, accommodation, and native products through brand influence, and expand income channels for poverty population.

\subsection{Deepen system reform}

Unlike ordinary tourism development, different with "civil administration poverty alleviation", "loan poverty alleviation" and "science and education poverty alleviation", tourism poverty alleviation is a brand-new intensive poverty alleviation method with higher requirements for system construction. Therefore, the key work of implementing tourism precision poverty alleviation in Sichuan Tibetan area should focus on deepening institutional reform is the key task. Sichuan Tibetan area should improve identification system according to the requirements of tourism development, pay attention to identify the willingness and participation ability of the poverty population based on the 
existing single poverty threshold identification, include the resource conditions, market conditions, supporting conditions and the economic, social and ecological benefits of tourism project into the tourism targeted identification system, establish a multi-dimension identification system for the target population, development conditions and development projects, and establish a dynamic identification mechanism at different stages of tourism development according to the differences in tourism participation degree of the poverty population. Therefore, while implementing tourism targeted poverty alleviation, it is necessary to must further perfect rural land approval system, and make full use of the housing ownership of the poverty population, homestead-land-use-right, the right to use collective construction land, land contractual management right, the collective forest right, and small water conservancy facilities, property rights, farmland property rights, promote land property right transfer, and try to use small-amount farmland use right mortgage for financing to increase the property population's income from participating in tourism development. It is necessary to perfect general transfer payment method, explore carbon credit, emissions trading, watershed ecological compensation and other systems, build multi-dimension ecological compensation mechanism, encourage poverty people in ecologically fragile areas to change means of livelihood, and actively participate in developing tourism industry.

\section{Acknowledgement}

This research was financially supported by the 2015 National Social Science Fund Key Project "Studies on Traditional Village Protection Path in Southwest Ethnic Areas in the Process of New-type Urbanization"(15AMZ010), Sichuan Social Science Research Planning Project "Studies on Sichuan-Tibet Demarcation in the Yongzheng Period and Tibet-governing Policy Transformation in Qing Dynasty" (SC17B001) and phased achievement of Aba Prefecture Social Science Special Fund Project "Studies on Non-Intangible Protection, Development and Utilization of Ethnic Areas under the Background of Rural Revitalization Strategy" (ABKT2018068).

\section{References}

[1] Xiao Yiran, Gong Xian. Studies on Tourism Poverty Alleviation and Income Increment of Farmers and Herdsmen in Tibetan Area-Taking Ganzi Tibetan Autonomous Prefecture as an Example, Journal of Yunnan Nationalities University(Philosophy and Social Sciences Edition), 2018(3):107- 113.

[2] Tu Deng Kezhu. Studies on poverty alleviation and income increment of farmers and herdsmen in Tibet, Journal of Tibet University(Social Science Edition), 2017(1):134-138.

[3] Geng Baojiang, Zhuang Tianhui, Peng Liangqin. Driving Mechanism and Micro-mechanism of Tourism Targeted Poverty Alleviation in Sichuan Tibetan Area, Guizhou Ethnic Studies, 2016(4): 157-160.

[4] Li Jia, Tian Li, Wang Lei. Studies on Tourism Targeted Poverty Alleviation Mechanism in Contiguous Extremely Poor Ethnic Areas__-Taking Sichuan Tibetan Area as an Example, Journal of Southwest University for Nationalities(Humanities and Social Sciences), 2017(6):116 -121.

[5] Liu Tian, Yang Tianchao. Studies on the Transformation of Tourism Poverty Alleviation Model in Sichuan Minority Villages, Journal of Ethnology,2016(6):85-89. 